\title{
Efeito-escola e estratificação escolar: o impacto da composição de turmas por nível de habilidade dos alunos
}

\author{
School effects and educational stratification: the impact of class \\ composition based on student ability level
}

\author{
Maria Teresa Gonzaga Alves* \\ José Francisco Soares**
}

\section{Resumo}

Este estudo mediu o efeito-escola no desempenho acadêmico dos alunos de sete escolas públicas que atendem a comunidades vizinhas relativamente homogêneas do ponto de vista socioeconômico. 0 efeito-escola foi mensurado através da identificação da parte do progresso dos alunos que pode ser atribuída às escolas. A pesquisa coletou dados longitudinais junto a todas as turmas de $5^{a}$ série do Ensino Fundamental no início e no final do ano letivo. Os alunos responderam a testes de Português (leitura) e Matemática e preencheram um questionário sobre suas características demográficas, socioeconômicas e culturais, itens sobre o percurso escolar e hábitos de estudo. Também foram realizadas entrevistas com profissionais das escolas e com familiares dos alunos com o objetivo de contextualizar os resultados obtidos com os instrumentos quantitativos. Os resultados revelam que o efeito-escola se estrutura pela forma como as escolas organizam os alunos em turmas. A formação das turmas por nível de habilidade impacta não apenas o nível de desempenho dos alunos, mas também as diferenças nas taxas de progresso observadas durante o estudo. Os critérios de formação de turmas contribuem para que pequenas diferenças entre os alunos se transformem em grandes diferenças entre os grupos e acirrem a estratificação escolar de uma forma mais ampla.

Palavras-Chave: Efeito-Escola; Efeito-Turma; Pesquisa Longitudinal

Doutora em Educação, pesquisadora do Programa de Pós-Graduação em Sociologia da Universidade Federal de Minas Gerais (Bolsista PRODOC) e do Grupo de Avaliação e Medidas Educacionais da Faculdade de Educação (GAME-FAE) da Universidade Federal de Minas Gerais. mtga@ufmg.br.

** Ph.D. em Estatística, professor do Departamento de Ciências Aplicadas à Educação da Universidade Federal de Minas Gerais e Coordenador do GAME/FAE - francisco-soares@ufmg.br. 


\section{Abstract}

This study measures the school effects on the achievement for fifth grade students of seven public schools, which serve homogeneous, in terms of their socioeconomic status, communities. The school effect is measured through a hierarchical linear model, which allows the separation of the learning of fifth grade students due to their schools practices from other sources of influence. The students included in this study were tested at the beginning and at the end of the school year. They answered a Portuguese language and a Mathematics test and filled a questionnaire with items on their demographic, socioeconomic and cultural characteristics. Additional items in the questionnaire captured the students' studying habits and their academic trajectory. Some parents and school staff were also interviewed in order to help the contextualization of the results, obtained with the achievement tests and questionnaires. The results show that the way the schools allocate students to classes has a large impact on student achievement. Using academic ability to allocate students to different classes impact not only the individual student achievement level, but also their corresponding learning rates. This class composition criterion contributes to transform small initial differences among students in large differences on their academic achievement, increasing therefore the school stratification.

Keywords: School Effects; Class Effects; Longitudinal Study

\section{INTRODUÇÃO}

Este texto discute a relação entre escolas e estratificação social, tomando como referência teórica os estudos no campo da Sociologia da Educação sobre desempenho escolar e a literatura sobre o efeito-escola. A referência empírica é a análise dos dados obtidos através de uma pesquisa longitudinal conduzida em escolas públicas sediadas em Belo Horizonte com o objetivo principal de medir o efeito-escola para o progresso acadêmico dos alunos.

Talvez uma das teses mais importante da Sociologia da Educação seja o argumento de que o desempenho escolar é fortemente associado à origem social dos alunos. O peso explicativo dos fatores extra-escolares, associados ao nível socioeconômico das famílias dos alunos, foi comprovado empiricamente através de grandes surveys educacionais conduzidos nos Estados Unidos, Inglaterra e outros países desenvolvidos, sobretudo nos anos 1960 (Forquin, 1995; Nogueira, 1990). Dentre os trabalhos da época, o mais destacado é o Relatório Coleman, lançado em 1966, que pesquisou milhares de estudantes norte-americanos e teve enorme impacto nas políticas públicas nos Estados Unidos e na Sociologia da Educação de forma geral. 
A pesquisa conduzida por Coleman e colaboradores (Coleman et al., 1966) respondeu à demanda do Governo e do Congresso norteamericanos, explicitada no documento Civil Right Act, de 1964, para que se investigasse a ausência de igualdade de oportunidades educacionais para os indivíduos em razão do sexo, da raça/cor, da religião ou da região de origem nas instituições públicas de ensino de todos os níveis no país. O estudo partiu da hipótese de que há uma relação entre a estrutura social e a conduta individual, e os autores procuraram responder qual dos sistemas sociais, o escolar ou o familiar, explicaria a maior parte das desigualdades no desempenho escolar, ou seja, qual seria a força ou a importância relativa de cada um. Os resultados, amplamente reportados, levaram à conclusão de que as escolas não fazem diferença.

Os estudos da Sociologia da Educação na França, principalmente com os trabalhos de Pierre Bourdieu e colaboradores, reforçaram essas conclusões. Com base nos dados longitudinais sobre as trajetórias escolares na França e também em pesquisas conduzidas nos meios universitários do país, esses autores inovaram ao destacar o peso do capital cultural na herança familiar definidora das trajetórias escolares (Bourdieu; Passeron, 1975). A teoria da reprodução proposta por Bourdieu, que relegou ao sistema de ensino o papel de mero reprodutor da estrutura da relação entre as classes sociais, teve uma extraordinária repercussão na pesquisa educacional e no ensino, na França e em vários países do mundo, inclusive o Brasil (Nogueira; Nogueira, 2004).

Os grandes surveys educacionais, posteriormente, sofreram inúmeras críticas metodológicas, ${ }^{1}$ mas eles foram fundamentais para o desenvolvimento da metodologia de pesquisas quantitativas em larga escala para avaliação educacional, implantadas sobretudo a partir dos anos 1980. Os novos estudos voltados para a problemática educacional, mesmo sem negar a forte conexão entre origem social e êxito escolar, de certa forma contribuíram para reduzir o forte pessimismo em relação às escolas, que dominou a Sociologia da Educação até os anos 1970, e para a emergência de uma sociologia da escola (Singly, 2000).

A pesquisa sobre o efeito-escola basicamente passou a defender a necessidade de "abrir a caixa preta" da escola, a fim de entender os processos escolares associados ao desempenho escolar, e também

1 Ver, por exemplo, Mosteller e Moynihan (1972); Sørensen e Morgan (2000). 
identificar escolas que por suas práticas pedagógicas conseguem levar alunos de origem social e cultural desfavorecida a resultados escolares que contrariam as expectativas (Bressoux, 2003). As novas pesquisas foram favorecidas por algumas transformações na política educativa dos principais países produtores de conhecimento na área sociológica e por mudanças nas pesquisas propriamente ditas. Em relação às políticas, as escolas se tornaram mais autônomas sob vários pontos de vista, e os sistemas de ensino mais descentralizados (Cousin, 2000). Quanto à pesquisa, a principal inovação se deu com o desenvolvimento de modelos e seus respectivos softwares, apropriados para a análise estatística de dados com variáveis medidas em múltiplos níveis, como é o caso da temática educacional, em que freqüentemente se estuda a relação entre níveis micro e macrossociais que interagem entre si (por exemplo, a relação entre os alunos, as salas de aula e as escolas, com análise através dos chamados modelos hierárquicos ou multinível). ${ }^{2}$

No Brasil, as pesquisas sobre o efeito-escola são bem recentes. Os primeiros resultados começaram a ser publicados a partir de meados dos anos 1990, quando o Instituto Nacional de Pesquisas Educacionais Anísio Teixeira (INEP), do Ministério da Educação, passou a disponibilizar dados produzidos pelo Sistema de Avaliação da Educação Básica (SAEB). Os resultados do SAEB chamaram muita atenção por mostrarem o quadro de enormes desigualdades educacionais no país (Barbosa; Fernandes, 2001; Soares et al., 2001). Concordando com a literatura internacional, o SAEB comprova que a maior parte da variação entre os resultados escolares pode ser explicada por fatores extra-escolares. Mesmo levando-se em conta que o sistema educacional brasileiro é extremamente estratificado do ponto de vista socioeconômico, ainda assim a proporção da variação nos resultados escolares associada às escolas é muito maior do que os valores usualmente encontrados nas pesquisas realizadas nos países desenvolvidos. Soares et al. (2004), por exemplo, analisaram os dados produzidos na edição 2003 do SAEB e estimam que o efeito das escolas brasileiras (com o controle da situação socioeconômica dos alunos) varia em média entre $14 \%$ e $22 \%$, dependendo da série e da disciplina (matemática ou língua portuguesa). Esses valores são bem superiores aos observados na maioria

2 Detalhes técnicos sobre modelos hierárquicos podem ser consultados na literatura especializada, por exemplo, Goldstain (1995); Hox (1995); e Raudenbush e Bryk (2002). Em português, uma boa referência é o livro de Ferrão (2003). 
dos países desenvolvidos, por exemplo, os que participaram do Programa Internacional de Avaliação dos Alunos (PISA), que giram em torno de $10 \%$.

Apesar de esses resultados serem muito relevantes, são baseados em pesquisas com desenhos metodológicos limitados. O SAEB coleta dados transversais, embora se saiba que para investigar o efeito-escola é sempre melhor dispor de dados longitudinais que permitem analisar o quanto as escolas agregaram aos alunos devido às suas políticas e práticas (Goldstein et al., 1999). O foco da análise da pesquisa sobre o efeitoescola não deve ser apenas o aprendizado do aluno em um determinado estágio de sua vida escolar, mas, principalmente, o processo de aprendizagem, porque se reconhece que as escolas só podem ser responsáveis pelo que ocorre durante o tempo que o aluno esteve na própria escola. A aprendizagem diz respeito à aquisição de conhecimentos, de habilidades, de crescimento intelectual ou físico etc., o que é central para a educação e para a escola. Mas as escolas recebem alunos com níveis de conhecimento diferenciados e a aprendizagem dificilmente é uniforme no tempo, e tampouco no indivíduo. Ela varia em função de características dos alunos, mas também em função da organização escolar e das práticas pedagógicas.

Neste estudo, são apresentados os resultados obtidos com a análise dos dados de uma pesquisa longitudinal que tem um alcance mais longo que o aqui destacado. ${ }^{3}$ Esta reflexão foi estimulada pela análise intermediária dos dados empíricos coletados em dois momentos dentro de um mesmo ano letivo, quando se constatou o efeito das turmas nos resultados dos alunos. Isso nos pareceu suficientemente relevante para merecer o registro neste texto, haja vista que a análise final dos dados longitudinais completos tem um enfoque diferente (Alves, 2006).

3 Os dados analisados neste estudo foram obtidos no âmbito de uma pesquisa de doutorado cujo objetivo principal é medir o efeito-escola para o processo de aprendizagem nas áreas de matemática e leitura. Esta inclui informações obtidas em uma terceira onda de coletas de dados, quando os alunos estavam concluindo a $6^{\text {a }}$ série do Ensino Fundamental. 0 enfoque da análise conduzida na pesquisa de doutorado ultrapassa, portanto, a abordagem deste artigo, porque analisa a trajetória dos alunos durante dois anos letivos. Além disso, esta pesquisa constituiu um estudo-piloto do projeto "Estudo Longitudinal da Geração Escolar 2005 - GERES”, do Grupo de Avaliação e Medidas Educacionais - GAME/FAE/ UFMG, que teve início em 2005. O GERES acompanhará uma coorte de alunos a partir da $1^{\text {a }}$ série até a $4^{\text {a }}$ série, em 60 escolas (públicas e particulares) de Belo Horizonte. 0 projeto acontece simultaneamente em outras quatro cidades brasileiras (Rio de Janeiro, Salvador, Campinas e Campo Grande). Esta pesquisa-piloto foi um dos pilares para a preparação do projeto GERES. Sobre o GERES, consultar <http://www.geres.ufmg.br>. 


\section{O problema da pesquisa}

O sistema de ingresso nas escolas públicas de Belo Horizonte para crianças com seis ou sete anos de idade é conduzido oficialmente através do Cadastro Escolar, ${ }^{4}$ que, a princípio, viabiliza que os alunos estudem próximo de suas residências. ${ }^{5}$ Poder-se-ia supor, assim, que o alunado das escolas públicas refletisse a composição demográfica de sua vizinhança. Mas na realidade não é bem isso o que ocorre, porque o sistema educacional é fortemente segmentado por filtros socioeconômicos e culturais, que produzem um efeito de seleção em toda a rede escolar. As escolas públicas são super-representadas por alunos oriundos dos setores mais pobres da sociedade, mesmo quando inseridas em bairros de classe média ou alta, enquanto a maioria dos alunos oriundos das famílias com maior poder aquisitivo estão predominantemente nas escolas privadas.

Não obstante essa prévia segmentação, o Cadastro Escolar é um sistema que pretende ser neutro, garantindo para todas as crianças uma vaga nas escolas, que, a princípio, deveriam ter a mesma qualidade de ensino. De fato, a heterogeneidade entre as escolas públicas é bem menor do que a diversidade de padrões observada na rede particular. ${ }^{6}$ Mas, na verdade, o sistema oficial de ingresso na escola não consegue garantir uma distribuição neutra das crianças entre as escolas, pois há mecanismos informais, que influem na seleção e na composição do alunado. Os pais nem sempre estão dispostos a aceitar a vaga destinada ao seu filho pelo sistema oficial e podem se tornar sujeitos muito ativos na busca de uma

4 O Cadastro Escolar, realizado conjuntamente pelas secretarias de educação do Estado e do Município, identifica o público para ingresso no ensino fundamental e leva em consideração a demanda e o número de vagas nas escolas. Informações disponíveis no site da Prefeitura Municipal de Belo Horizonte: <http://www.pbh.gov.br>.

5 Há outros mecanismos oficiais de alocação dos alunos conduzidos nas escolas. Um deles é a parceria entre escolas, que garante a continuidade dos alunos que estudam em escolas que oferecem apenas as quatro séries iniciais, mas os alunos têm suas vagas garantidas em uma outra escola da região que oferece as séries seguintes. Outro é o processo para transferências que ocorrem durante a vida escolar do aluno (no meio de um ano letivo ou entre séries) por mudança de endereço ou outro motivo. Nesse caso, a obtenção da vaga depende da procura e, geralmente, há um sorteio.

6 O SAEB mostra que as escolas públicas são mais semelhantes entre si do que as escolas particulares, que se tornam mais heterogêneas à medida que se passa da $4^{a}$ para a $8^{a}$ série do ensino fundamental, e desta para o $3^{\circ}$ ano do ensino médio. Apesar de serem em número muito inferior (no nível de ensino fundamental, mais de $90 \%$ das crianças estão na rede pública, segundo dados do Censo Escolar de 2003), as escolas particulares oferecem muito mais diversidade de oportunidades educacionais e tipos de estabelecimentos de ensino (Soares et al., 2004). 
vaga na escola pública desejada, porque têm uma percepção, muitas vezes difusa, do ambiente social e da qualidade acadêmica das escolas. Por exemplo, uma escola que tenha uma boa reputação pode atrair alunos mais preparados e motivados, enquanto uma escola que é percebida pela comunidade como tendo problemas de violência interna ou externa pode ser rejeita por algumas famílias. Assim, pais com essa orientação freqüentemente burlam o Cadastro Escolar com um endereço falso para conseguir vaga na escola preferida. Se o pai não consegue a vaga para o filho na escola desejada, ele pode tentar ajuda de algum conhecido no sistema escolar (principalmente no caso de transferência) ou até mesmo acionar a justiça.

Juntos, os mecanismos formais e informais para o ingresso dos alunos das escolas públicas formam um "ecossistema escolar" (Yair, 1996), no sentido de que as escolas de uma mesma região constroem um equilíbrio próprio frente ao seu público potencial. Em Belo Horizonte, as escolas de uma mesma região cumprem esse papel quando elas atendem à demanda local, através do Cadastro Escolar, mas também convivem com práticas informais para a obtenção de vagas que quebram a lógica formal. Porém, isso não provoca inicialmente nenhum desequilíbrio, porque as escolas, de certa forma, se complementam na função de atender aos diferentes tipos de alunos e famílias da região. Os mecanismos de alocação dos alunos entre as escolas criam uma divisão entre, de um lado, as escolas que são mais "escolhidas", ou seja, têm uma parcela expressiva de seu alunado que ingressou na escola devido à ação mais ativa de seus pais (burla de endereço, clientelismo, justiça etc.), e, de outro, as escolas que são mais "aceitas" e que atendem predominantemente à vizinhança mais próxima da escola.

Esses fatores, que são externos às escolas, interferem na formação do alunado em suas oportunidades de aprendizagem, assim como na estratificação do sistema escolar. Mas as escolas também têm um peso nesse processo, na medida em que as suas políticas e práticas pedagógicas podem estruturar tais desigualdades no âmbito escolar. O efeito-escola refletirá, portanto, a conjunção de fatores externos e internos, fundamentais para definir as oportunidades educacionais dos alunos.

Nesta pesquisa, foram selecionadas sete escolas públicas da mesma região administrativa de Belo Horizonte. Considerando as características em comum que permitiriam controlar minimamente a heterogeneidade entre as escolas (todas públicas, que atendem a um alunado menos 
privilegiado economicamente e localizadas na mesma região da cidade) em um cenário ideal não existiriam diferenças entre elas. $\mathrm{O}$ efeito-escola seria próximo de zero para todas as escolas e a expectativa de progresso dos alunos seria a mesma em qualquer uma delas. Por outro lado, se houver diferença entre as escolas, mesmo levando-se em conta a diversidade do alunado, provavelmente isso refletirá o efeito de processos e práticas pedagógicas das escolas.

Tendo em vista as características do campo da pesquisa, basicamente, este estudo procura responder a duas questões:

1. Qual o progresso no aprendizado dos alunos em matemática e leitura dentro de um ano letivo?

2. Como as características do contexto escolar e do alunado afetam o progresso dos alunos nesse período?

Com essas questões objetivas, o trabalho procura discutir o efeitoescola e as conseqüências em termos de estratificação escolar. Naturalmente, por se tratar de um estudo-piloto, este apresenta limites muito claros, e as respostas para as questões colocadas constituem evidências que precisam ser mais bem analisadas em contextos mais amplos. Por isso, muitas das análises só puderam ser realizadas à luz das evidências qualitativas colhidas através de entrevistas realizadas nas escolas e com familiares dos alunos.

\section{Os DADOS}

Esta pesquisa tem um desenho longitudinal, com coleta de dados em três ondas, durante os anos de 2003 e 2004. Neste estudo, analisamos os dados obtidos nas duas primeiras ondas, que ocorreram durante $\mathrm{O}$ primeiro ano letivo do estudo, quando os alunos freqüentavam a $5^{\text {a }}$ série ou ciclo equivalente.

Em cada onda, todos os alunos de todas as turmas respondem a testes de língua portuguesa (com ênfase na leitura e compreensão de textos), de matemática e a um questionário contextual para levantamento de informações sobre as características demográficas, socioeconômicas e culturais dos alunos e de suas respectivas famílias, além de itens sobre o percurso escolar e hábitos de estudo.

Os testes da primeira onda foram compostos por itens pré-testados do Banco de Itens do GAME, disponibilizados e publicados pelo SAEB. 
Esses testes foram iguais em todas as escolas. $\mathrm{Na}$ segunda onda, os testes foram recompostos com novos itens, mas mantendo alguns itens da primeira onda para fins de equalização entre as proficiências dos dois testes. Entre os novos itens, alguns vieram do Banco de Itens do GAME e outros foram elaborados pelos professores das escolas responsáveis pelas disciplinas de matemática e de língua portuguesa nas séries testadas. Assim, na segunda onda, cada escola teve um teste próprio composto por itens exclusivos a ela, mas mantendo os itens externos em comum com as outras escolas e itens comuns com o teste anterior, o que é fundamental em um estudo longitudinal.

A amostra inclui alunos de 28 turmas de sete escolas, perfazendo um total de 740 alunos que fizeram o teste de língua portuguesa e 749 que fizeram o de matemática.

Além de coletar dados quantitativos, foram realizadas entrevistas com profissionais das escolas (professores, diretores, supervisores ou coordenadores) e com familiares dos alunos selecionados a partir dos resultados nos testes. ${ }^{7} \mathrm{O}$ objetivo das entrevistas foi compreender os processos escolares e os fatores familiares mais diretamente relacionados ao desempenho dos alunos.

Neste trabalho, as escolas são referidas por números: escola 1, escola 2 etc.

\section{Medida do desempenho escolar}

Os resultados dos testes da primeira e da segunda ondas foram transformados em proficiências, o que é uma evidência da aprendizagem dos alunos expressa através de um parâmetro de modelo da Teoria de Resposta ao Item (TRI). A TRI produz escalas especialmente adequadas para comparações espaciais ou temporais de resultados obtidos em estudos que envolvem alunos distribuídos em diferentes séries ou em diferentes

Foram realizadas trinta e oito entrevistas com famílias de alunos e vinte e duas com profissionais das escolas.

8 A proficiência é diferente do número de acertos. O valor para cada aluno é calculado ponderando-se, com pesos empiricamente obtidos, os resultados de cada item dos testes. Os pesos usados refletem idéias simples, como a de que um acerto em um item mais difícil fornece maior evidência de alta proficiência do que um acerto de um item fácil (Baker, 2001; Fletcher, 1994). 
momentos da trajetória escolar. A escala utilizada nesta pesquisa é a mesma do SAEB, cujos valores típicos variam entre 100 e 500.

Neste trabalho, a variável resposta é o ganho do aluno ao final do primeiro ano letivo, obtido pela diferença entre a proficiência da segunda onda pela primeira. Este aspecto é uma novidade no campo dos estudos de avaliação educacional. Em geral, os levantamentos realizados no país, como, por exemplo, o Sistema Mineiro de Avaliação (SIMAVE), a versão mineira do SAEB, comparam o nível acadêmico das escolas com padrões de referência externos. Espera-se que o conjunto dos alunos das escolas atinja uma determinada média para que o ensino em cada escola seja considerado satisfatório na disciplina avaliada. Com a análise do ganho dos alunos é possível apreciar o seu crescimento, independentemente de qual tenha sido o ponto de partida, que é sempre muito diferente entre as escolas.

\section{Descrição dos dados}

As sete escolas estão situadas na mesma região administrativa de Belo Horizonte, a regional Pampulha. Foram escolhidas a partir de 17 escolas públicas estaduais e municipais da região. As escolas foram selecionadas de acordo com a possível semelhança entre seu alunado ou por compartilharem a vizinhança mais próxima.

$\mathrm{Na}$ tabela a seguir, estão sintetizadas algumas informações sobre as escolas, obtidas no questionário dos alunos e no Censo Escolar. Comentaremos alguns aspectos. 


\section{Tabela 1}

Descrição das escolas

\begin{tabular}{|c|c|c|c|c|c|c|c|}
\hline & Escola 1 & Escola 2 & Escola 3 & Escola 4 & Escola 5 & Escola 6 & Escola 7 \\
\hline Rede & Estadual & Estadual & Estadual & Estadual & Municipal & Municipal & Municipal \\
\hline$N^{\circ}$ alunos da escola & 845 & 1669 & 1555 & 2837 & 1079 & 1792 & 733 \\
\hline $\mathrm{N}^{\circ}$ alunos da $5^{\mathrm{a}}$ série & 142 & 149 & 115 & 187 & 119 & 156 & 99 \\
\hline$N^{\circ}$ turmas de $5^{a}$ série & 4 & 4 & 3 & 5 & 4 & 5 & 3 \\
\hline $\begin{array}{l}\text { Tamanho médio das } \\
\text { turmas }\end{array}$ & $\begin{array}{l}35,5 \\
(3,3)\end{array}$ & $\begin{array}{l}37,3 \\
(2,1)\end{array}$ & $\begin{array}{l}38,3 \\
(0,6)\end{array}$ & $\begin{array}{l}37,4 \\
(2,1)\end{array}$ & $\begin{array}{l}29,8 \\
(4,7)\end{array}$ & $\begin{array}{l}31,2 \\
(5,9)\end{array}$ & $\begin{array}{l}33,0 \\
(2,0)\end{array}$ \\
\hline $\begin{array}{l}\text { Nível } \\
\text { socioeconômico } \\
\text { médio* }\end{array}$ & $\begin{array}{l}-0,39 \\
(0,59)\end{array}$ & $\begin{array}{l}0,23 \\
(0,51)\end{array}$ & $\begin{array}{l}0,22 \\
(0,62)\end{array}$ & $\begin{array}{l}0,00 \\
(0,56)\end{array}$ & $\begin{array}{l}-0,31 \\
(0,58)\end{array}$ & $\begin{array}{l}-0,16 \\
(0,66)\end{array}$ & $\begin{array}{l}-0,15 \\
(0,52)\end{array}$ \\
\hline $\begin{array}{l}\% \text { alunos bolsa- } \\
\text { escola }\end{array}$ & $22,2 \%$ & $5,1 \%$ & $10,8 \%$ & $7,9 \%$ & $37,8 \%$ & $28,5 \%$ & $19,3 \%$ \\
\hline $\begin{array}{l}\text { \% distorção idade- } \\
\text { série }\end{array}$ & $24 \%$ & $9 \%$ & $13 \%$ & $16 \%$ & $13 \%$ & $7 \%$ & $7 \%$ \\
\hline $\begin{array}{l}\% \text { alunos que vão a } \\
\text { pé para a escola }\end{array}$ & $78,4 \%$ & $30,1 \%$ & $15,7 \%$ & $27,3 \%$ & $70,3 \%$ & $41,9 \%$ & $57,3 \%$ \\
\hline $\begin{array}{l}\% \text { alunos novatos na } \\
\text { onda } 1\end{array}$ & $21,4 \%$ & $18,4 \%$ & $6,2 \%$ & $100 \%$ & $38,8 \%$ & $75,0 \%$ & $18,8 \%$ \\
\hline
\end{tabular}

Fonte: Questionário do aluno (exceto o número de alunos, obtido no Censo Escolar 2003).

* Nota: O indicador do nível socioeconômico dos alunos foi construído com os itens: escolaridade dos pais, a posse de bens de conforto (automóvel, vídeo, máquina de lavar roupas etc.), número de banheiros e a presença de empregada doméstica na residência do aluno. A escala obtida tem valores típicos entre -3 e 3 . Os itens são os mesmos utilizados para o cálculo do Critério Brasil de Classificação econômica, mas o cálculo foi realizado através de um modelo da Teoria da Resposta ao Item (TRI).

As escolas têm tamanhos muito variados, conforme os números de alunos apresentados na tabela, o que dá uma dimensão do grau de complexidade da gestão de cada uma delas. As escolas estaduais têm turmas, em média, maiores que as das escolas municipais, o que é um fator que impacta as condições de trabalho nas escolas.

Em seguida, destaca-se o nível socioeconômico médio das escolas e o percentual de alunos com bolsa-escola. Esses dois indicadores caminham na mesma direção: as escolas 2, 3 e 4 têm um alunado, em média, mais privilegiado, e o percentual de alunos com bolsa-escola é bem inferior nestas do que nas outras. Mas a média do nível socioeconômico mascara o fato de que internamente as escolas são bem heterogêneas, haja vista o tamanho dos desvios-padrão. Isso pode ser 
visualizado no gráfico de caixas, ${ }^{9}$ abaixo, que mostra a distribuição da variável nível socioeconômico nas escolas. Pelo tamanho das caixas e das linhas de suporte, acima e abaixo, fica evidente a dispersão dos dados nessa variável. Outra observação em relação ao gráfico é que a heterogeneidade interna nas escolas contribui para torná-las mais parecidas entre si. Nota-se que a maioria dos alunos se concentra entre os valores - 1 e 1 , numa escala cujos valores típicos vão de -3 a $3 .{ }^{10}$ Além disso, todas as caixas se interserem, apesar disso ser bem menos intenso entre as escolas 1 e 5 do que em relação às escolas 2 e 3.

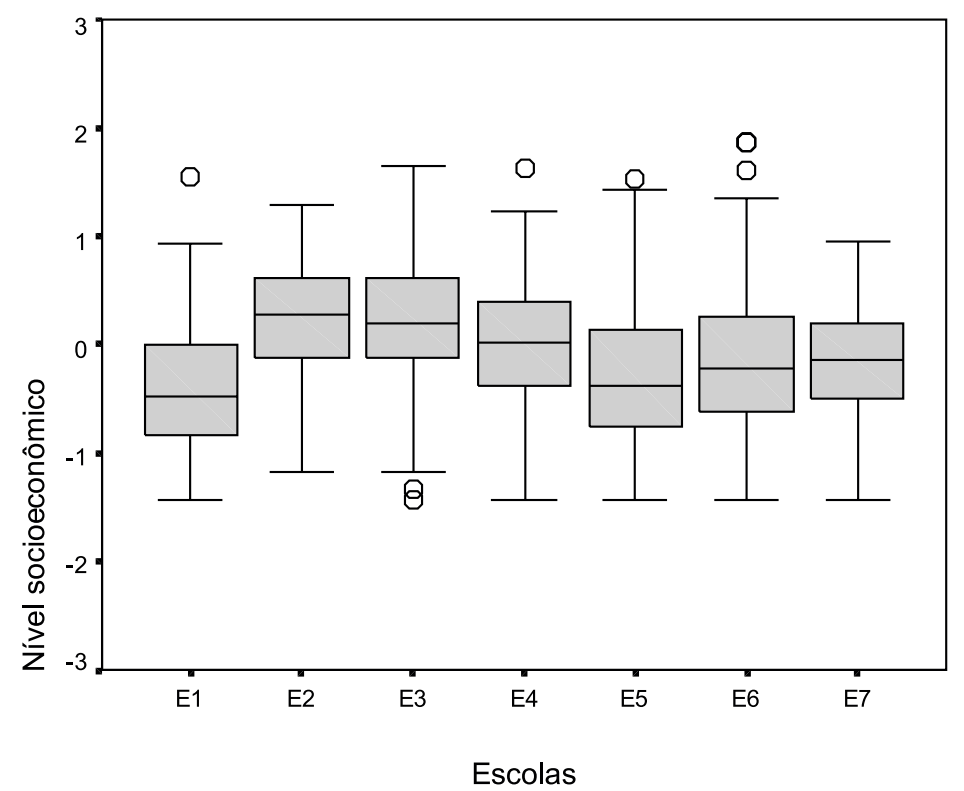

GRÁFICO 1 - Distribuição do nível socioeconômico dos alunos por escolas Fonte: questionário do aluno.

$9 \quad$ O gráfico de caixas (Box-plot) consiste em uma caixa e dois suportes. O meio da caixa é identificado pela mediana dos dados e marcado por uma linha horizontal. 0 extremo inferior é identificado pelo primeiro quartil (Q1) e o topo pelo terceiro quartil (Q3). Os suportes são as linhas que se estendem do topo e do fundo da caixa até os valores mais baixos e mais altos, na região definida pelos limites: inferior Q1 - 1,5 (Q3 - Q1) e superior $\mathrm{Q} 1+1,5(\mathrm{Q} 3-\mathrm{Q} 1)$.

10 Vale registrar que essa distribuição apresenta um comportamento bem diferente daquele que observaríamos em um estudo em larga escala, que normalmente encontra uma dispersão bem maior dos resultados ao longo da escala, por exemplo, na comparação entre escolas das redes pública e privada, ou por regiões do país (Soares et al., 2004). 
O problema da defasagem idade-série ocorre por repetência ou por evasão e posterior reingresso na escola. As redes de ensino de Minas Gerais e de Belo Horizonte adotaram políticas para corrigir o fluxo de alunos das escolas públicas, como a organização do ensino em ciclos e a progressão continuada, mas o problema está longe de ter uma solução satisfatória. Alunos defasados têm desempenho inferior aos alunos com idade correta, e nas escolas onde esta diferença não é significativa a eqüidade entre os alunos com defasagem idade-série e com idade adequada ocorre numa situação de desempenho escolar insatisfatório para todos (Ferrão et al., 2002). Na Tabela 1 observa-se que os maiores percentuais de alunos com defasagem idade-série se encontram nas escolas 1, 4, 3 e 5, nesta ordem. Ou seja, o problema se destaca tanto em escolas com nível socioeconômico médio mais baixo (escolas 1 e 5), quanto nas escolas com situação um pouco mais favorável (3 e 4).

O percentual de alunos que vão a pé para a escola oferece uma idéia do grau de inserção das escolas na comunidade mais próxima. A hipótese é que alunos que vêm a pé são os que vivem no entorno mais próximo da escola, sendo, portanto, os beneficiários diretos do Cadastro Escolar. Na escola 3, a maioria dos alunos vive distante da escola, pois necessita de algum tipo de transporte para chegar até lá. Em seguida, vêm as escolas 2 e 4, com cerca de 30\% de alunos que vão a pé, ou seja, a maioria também não vive tão perto da escola. A escola 6 tem uma situação intermediária, e as escolas 1, 5 e 7 têm maioria dos alunos que vão a pé para a escola. ${ }^{11}$

O efeito-escola será mais forte quanto mais longa for a vida escolar do aluno na escola. Mortimore et al. (apud Bressoux, 2003), por exemplo, mostrou que há um efeito cumulativo da escola, que é muito mais forte após três anos na mesma escola do que após somente um ano. $\mathrm{O}$ indicador de alunos novatos dá uma idéia da rotatividade do alunado nas escolas, apesar de não ter validade para as escolas 4 e 6 (pelo menos no primeiro ano da pesquisa), porque estas escolas formam turmas de $5^{a}$ série sobretudo com alunos egressos de escolas parceiras que oferecem ensino somente

11 Esses dados sugerem, ainda que de forma indireta, que os alunos das escolas 3, 4 e 2, nesta ordem, são de famílias mais "ativas" na escolha da escola do filho, enquanto nas demais escolas predominam alunos de famílias mais "passivas". Os que utilizam algum meio de transporte são os alunos cujos pais fizeram a "escolha" da escola e por isso estão dispostos a arcar com o custo do transporte, que fica bem mais caro do que o transporte urbano por ônibus coletivo. Esta questão específica foi explorada em entrevistas com as famílias dos alunos. 
até a $4^{\text {a }}$ série. ${ }^{12}$ Entre as outras escolas, destaca-se a escola 5, onde quase $40 \%$ dos alunos são novatos, e a escola 3, pela baixa rotatividade.

\section{Os ganhos no primeiro ano da Pesquisa}

Os dois gráficos a seguir sintetizam os ganhos médios dos alunos da primeira para a segunda onda, em matemática e língua portuguesa. ${ }^{13}$

\section{Diferença entre onda 2 e onda 1 - Média das Escolas}

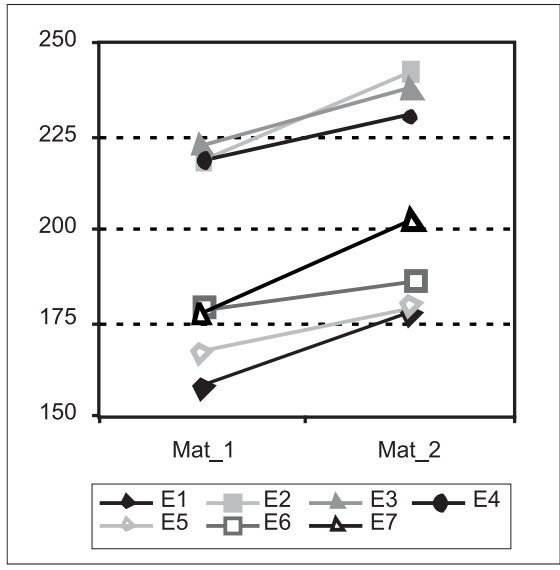

GRÁFICO 2 - Matemática

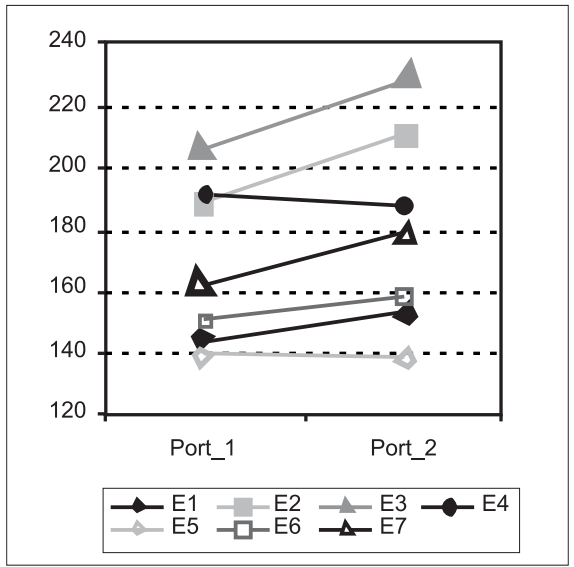

GRÁFICO 3 - Língua Portuguesa

Como observação inicial, nota-se que os resultados da primeira onda sugerem uma hierarquia das escolas em dois grupos bem distintos: o primeiro reúne as escolas cujos alunos têm um desempenho médio mais alto (escolas 2, 3 e 4), e o segundo, as escolas com desempenho mais baixo (escolas 1, 5, 6 e 7). No entanto, ao observar o que ocorre na segunda

12 A escola 4 começa o ensino na $5^{\text {a }}$ série, por isso $100 \%$ são novatos. No entanto, mais $70 \%$ dos novos alunos vêm de uma escola estadual próxima, que atende somente até a $4^{a}$ série. Situação parecida ocorre na escola 6 , que até a $4^{a}$ série tem apenas duas turmas. $\mathrm{Na} 5^{\mathrm{a}}$ série, a escola recebe os alunos egressos de uma escola estadual da vizinhança e $64 \%$ dos alunos da $5^{\mathrm{a}}$ série vêm do estabelecimento vizinho. Portanto, a maioria dos alunos das $5^{\mathrm{a}}$ séries das escolas 4 e 6 tem a marca da escola anterior e o seu desempenho, no final do primeiro ano da pesquisa, deve refletir pouco o efeito da atual escola.

13 O curto intervalo de tempo que transcorreu entre as duas ondas (nove a dez meses) constitui uma limitação para a análise dos ganhos no período. Nos estudos sobre o efeito de escolas baseados em modelos de análise com duas medidas (tendo o desempenho prévio como variável controle), encontramos sempre um intervalo maior entre as observações, sendo o período de dois a três anos o mais freqüente (Lee; Bryk, 1989; Lee, 2000; Pituch, 1999; Bressoux, 1995), pois é preciso tempo para que o efeito-escola se destaque de outros fatores. Essa questão foi contemplada com os dados da terceira onda. Nas tabelas do Apêndice, há uma síntese numérica dos ganhos médios com os respectivos intervalos de confiança, por escolas e por turmas. 
onda, a hierarquização entre as escolas não fica tão clara, principalmente em língua portuguesa.

Isso se liga à segunda observação, que é a da grande diferença em relação aos ganhos nas duas disciplinas, o que pode ser apreciado pela diferença na inclinação das retas nos dois gráficos. Os resultados de língua portuguesa são, de maneira geral, piores do que os de matemática. Em matemática, a média de desempenho de todas as escolas cresceu entre as duas ondas, mas houve retrocesso em língua portuguesa na escola 4, enquanto a escola 5 praticamente ficou na mesma posição. Esses resultados sugerem que as escolas podem ter efeitos diferenciados dependendo da área do currículo. Nuttall e colaboradores (apud Wyatt, 1996) encontraram resultados semelhantes com dados norte-americanos e concluem que não é possível fazer uma divisão simplista entre escolas boas e ruins, mesmo em áreas tão básicas como leitura e matemática.

A última observação, diz respeito aos ganhos no período. Destacamse, em matemática, as escolas 2 e 7 , cujas médias cresceram cerca de 25 pontos no período. A escola 5 também, se considerarmos o intervalo de confiança (cf. tabela do Apêndice). Em língua portuguesa, além das escolas 2 e 7, também os alunos da escola 3 tiveram ganhos médios consideráveis.

Esses resultados sugerem que, em alguns casos, o efeito-escola pode refletir o estabelecimento como um todo, por exemplo, os alunos das escolas 2 e 7 têm desempenhos muito semelhantes nas duas disciplinas. Esta aparente estabilidade precisa, no entanto, se manter por mais tempo, para que se possa concluir com mais segurança se isso é resultado do impacto das políticas e práticas do estabelecimento escolar. Mas outras escolas parecem ser bem mais sensíveis às variações que ocorrem internamente (entre alunos e entre turmas) ou entre as diferentes áreas de conhecimento, o que sugere uma maior fragmentação da organização escolar. Mais importante ainda é mostrar as diferenças nas trajetórias dos alunos em apenas um ano letivo. Isso reforça a importância de dados longitudinais para se medir o efeito-escola.

Quando se analisa o que ocorreu no nível das turmas, os resultados são também muito interessantes. ${ }^{14}$ Em todas as escolas, observa-se uma clara hierarquia entre as turmas na primeira onda. Porém, na segunda onda, as diferenças entre turmas (em algumas escolas ou disciplinas) aumentam, em outras diminuem ou ficam praticamente constantes.

14 Confira os resultados dos ganhos no nível das turmas que estão nas tabelas do Apêndice. Por questão de espaço não iremos apresentar os gráficos para as turmas. 
Em geral, a diferença entre as turmas aumenta quando a escola agrupa alunos por nível de habilidade que, via de regra, coincide com o nível socioeconômico. Por exemplo, uma das turmas da escola 1 reúne $40 \%$ de alunos com defasagem idade-série, e são os alunos com nível socioeconômico médio mais baixo da escola. Essa turma teve trajetória negativa durante o ano. $\mathrm{Na}$ escola 5 , a turma que mais progrediu foi a que era, na primeira onda, a melhor da escola. Na segunda onda, esta turma se destacou mais ainda, e pode-se dizer que todo o efeito da escola 5 se deve ao desempenho dos alunos desta turma, que reúne os alunos com nível socioeconômico médio mais elevado dentro da escola.

A diferença entre as turmas diminuiu principalmente quando os critérios de composição das turmas são mais neutros. $\mathrm{Na}$ escola 4 isso ocorreu, mas num cenário geral negativo, pois algumas turmas progrediram e outras tiveram trajetória negativa, convergindo todas pra uma média geral mais baixa. $\mathrm{Na}$ escola 7 houve resultados positivos tanto na média geral do progresso das turmas quanto no equilíbrio, pois o desempenho médio das turmas ficou mais parecido na segunda onda, nas duas disciplinas. É característica dessas duas escolas a heterogeneidade das turmas em relação ao nível socioeconômico. Mas a escola 7 conta com a vantagem de ser uma escola menor, o que aparece na literatura como favorável ao trabalho com turmas heterogêneas (Cohen, 2000).

Os resultados por turmas sugerem que o efeito-escola depende mais do nível das turmas. Às vezes, as diferenças entre as turmas aparecem apenas em uma disciplina, o que sugere uma dificuldade associada ao professor. Mas, na maioria das vezes, as diferenças não são localizadas, indicando que se trata do resultado das diferenças nas oportunidades de aprendizagem de cada grupo, conforme o perfil das turmas.

\section{Modelos de análise para os ganhos dos alunos}

O objetivo desta seção é apresentar os modelos para análise dos ganhos obtidos pelos alunos no primeiro ano do estudo longitudinal. Diante das evidências obtidas a partir das análises descritivas, a ênfase será dada aos resultados no nível das turmas, ${ }^{15}$ através de modelos hierárquicos, considerando os níveis turma e aluno.

15 Em análises prévias, foram elaborados modelos com três níveis (escola, turmas e alunos), mas a variabilidade no nível das escolas é muito pequena, quando se controla o fator contextual. Além disso, o número de escolas muito pequeno $(\mathrm{N}=7)$ afeta bastante a confiabilidade das estimativas. Por isso, a opção por destacar apenas os dois níveis. 
Para descrever o efeito das turmas foram elaborados dois tipos de modelos. No primeiro não se incluem variáveis explicativas. É o modelo nulo (ou incondicional), que dá uma descrição da proporção da variação entre as turmas. O segundo modelo controla os resultados pela composição do alunado das turmas. ${ }^{16}$

O resultado do modelo nulo, apresentado na Tabela 2, mostra que apenas $6 \%$ da variação nos ganhos em matemática ocorrem entre as turmas e $94 \%$, entre os alunos dentro das turmas; em relação aos ganhos em português, a variação entre as turmas é de $16 \%$ e, entre os alunos, de $84 \%$.

Tabela 2

Partição da variância do modelo nulo

\begin{tabular}{lcc}
\hline Fonte da variação & $\begin{array}{c}\text { Matemática } \\
\%\end{array}$ & $\begin{array}{c}\text { Português } \\
\%\end{array}$ \\
\hline Entre turmas $\left(^{*}\right)$ & 6,0 & 16,0 \\
\hline Entre alunos & 94,0 & 84,0 \\
\hline
\end{tabular}

Nota: ${ }^{*}$ ) significativo ao nível de $1 \%$.

É difícil avaliar a magnitude desses números, sem parâmetros válidos para a realidade brasileira sobre os ganhos de alunos durante um ano letivo. Segundo a recomendação de Lee (2001) sobre os modelos hierárquicos, numa primeira análise, o resultado de matemática sugere que não valeria a pena investigar o efeito dessas turmas, pois praticamente toda a variação nos ganhos recai sobre as diferenças entre os alunos. Mas o resultado de português mostra outra tendência, e indica que há efeitos diferenciados das turmas em relação aos ganhos dos alunos, numa proporção que justifica a investigação dos seus efeitos.

Apesar do reduzido impacto das turmas para o ganho dos alunos, foram elaborados modelos de análise que levaram em conta a composição socioeconômica das turmas. Este fator é relatado na literatura educacional com um dos mais influentes na produção de desigualdades entre as escolas, na medida em que pode reproduzir no contexto escolar as desigualdades sociais mais amplas (Cohen, 2000) e influir nas interações em sala de aula, o que é encontrado na literatura como efeito dos pares (Rutter; Maughan, 2002). O modelo irá estimar o efeito conhecido como Tipo B,

16 Os modelos foram estimados com o software MLWin (Goldstein, 1995). 
que visa equalizar as escolas por seus respectivos alunados, conforme a descrição de Raundenbush e Willms (1995). ${ }^{17}$

O modelo final é o seguinte:

$$
\begin{aligned}
& Y 2_{i j}-Y 1_{i j}=\beta_{0 j}+e_{i j} \\
& \beta_{0 j}=\gamma_{00}+\gamma_{0 I} M N S E_{j}+u_{0 j}
\end{aligned}
$$

Nesta equação:

- $Y 2_{i j}-Y 1_{i j}$ é a variável resposta, os ganhos dos alunos, calculada pela diferença entre a proficiência do aluno $\boldsymbol{i}$ da turma $\boldsymbol{j}$, obtida na segunda onda, e a proficiência desse mesmo aluno, na primeira onda;

- $\beta_{0 j}$ representa a contribuição da turma $j$ para o ganho do aluno (corresponde à média dos alunos da turma);

- $e_{i j}$ é a contribuição única de cada aluno ij (desvios), a qual assumimos ter distribuição normal com média igual a zero e variância constante, ó$^{2}$;

- $\gamma_{00}$ representa a média global dos ganhos para todas as turmas;

- $\gamma_{01} M N S E_{j}$ é a variável de controle, nível socioeconômico médio da turma (escala de -3 a 3, obtida via TRI);

- $u_{0 j}$ é o desvio de cada turma em relação à $\gamma_{00}$. Sendo este resíduo ajustado pelo nível socioeconômico médio da turma, representa o efeito de cada turma para os ganhos dos alunos, após a equalização pela condição social do grupo.

A Tabela 3 apresenta os resultados do ajuste dos modelos.

17 O efeito Tipo B estima qual o desempenho da escola $X$ em comparação com outras escolas com características semelhantes, porque inclui, além das variáveis de controle associadas ao aluno, fatores contextuais que fogem ao controle da escola, oriundos da composição do corpo discente. 
Tabela 3

Estimativas do modelo final controlado pelo nível socioeconômico das turmas

\begin{tabular}{c|c|c}
\hline \multirow{2}{*}{ Intercepto } & Matemática & Português \\
\cline { 2 - 3 } & $\begin{array}{c}\text { Coeficientes } \\
\text { (erro-padrão) }\end{array}$ & $\begin{array}{c}\text { Coeficientes } \\
\text { (erro-padrão) }\end{array}$ \\
\hline \multirow{2}{*}{ MNSE } & 14,5 & 5,9 \\
& $(2,2)$ & $(0,07)$ \\
\hline \multirow{2}{*}{ Fonte de variação } & 18,0 & 34,1 \\
& $(6,5)$ & $(11,9)$ \\
\hline Entre turmas $\left(^{*}\right)$ & $\begin{array}{c}\text { Componente da } \\
\text { varî́ncia } \\
(\%)\end{array}$ & $\begin{array}{c}\text { Componente da } \\
\text { varímîncia } \\
(\%)\end{array}$ \\
\hline Entre alunos & 5,0 & 12,0 \\
\hline
\end{tabular}

Nota: $\left(^{*}\right)$ significativo ao nível de $1 \%$.

Os resultados são significativos para a explicação dos ganhos, principalmente em língua portuguesa. Conforme os valores da tabela, o coeficiente da variável nível socioeconômico médio da turma (MNSE) é positivo e significativo, tanto para matemática quanto para português. A cada incremento na escala de MNSE, o aluno obtém ganhos em matemática e principalmente em português, da primeira para a segunda onda da pesquisa. Ou seja, os alunos matriculados nas turmas que têm melhor posição social média ganham mais.

A variabilidade entre as turmas para os ganhos em matemática, que já era pequena no modelo nulo, ficou praticamente a mesma (de 6\% para 5\%). Mas em língua portuguesa, o controle pelo contexto das turmas reduziu a variabilidade entre as turmas de $16 \%$ para $12 \%$ num patamar significativo. A evidência é que, apesar de não haver uma grande heterogeneidade no nível socioeconômico dos alunos de uma forma geral, dependendo do critério de formação das turmas, as pequenas diferenças são acirradas e contribuem para a estratificação interna nas escolas, que podemos captar com os resultados de português.

Para observar como esses resultados aparecem no nível de cada uma das turmas, os gráficos a seguir apresentam os resíduos desses modelos e os respectivos intervalos de confiança. Nos gráficos, os resíduos, simbolizados por triângulos, indicam os efeitos únicos de cada uma das turmas. As linhas acima e abaixo dos triângulos representam os respectivos intervalos de confiança. As linhas pontilhadas separam as escolas, e as turmas dentro de cada escola estão numeradas no eixo X. 


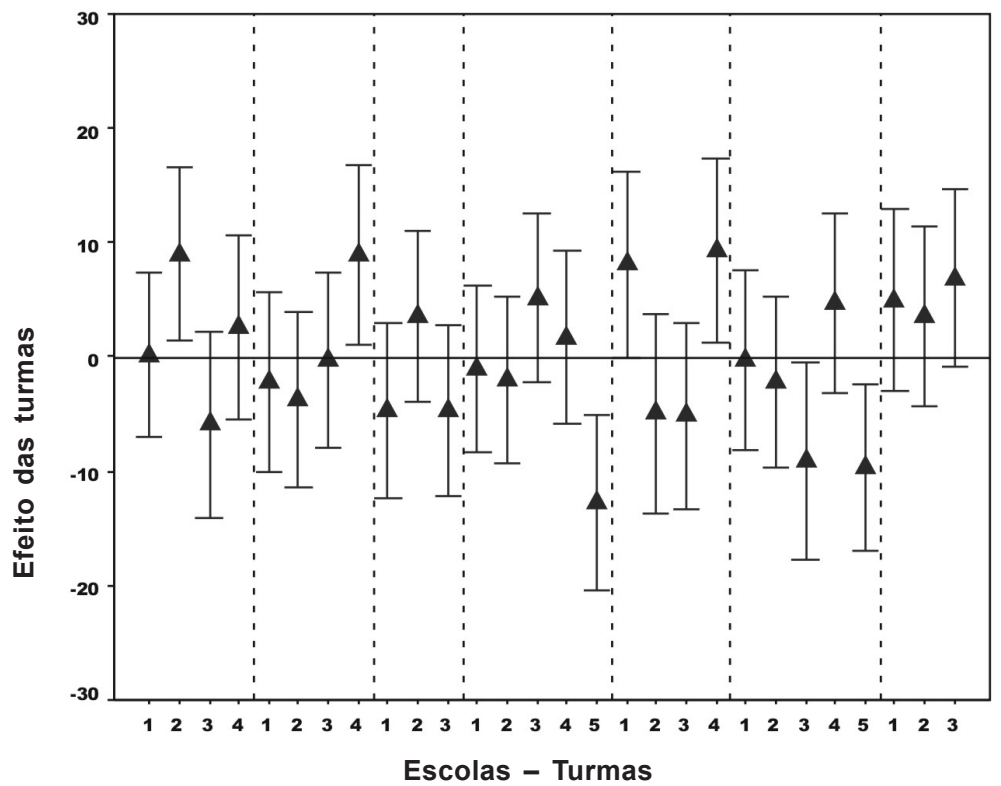

(*) Intervalo de confiança de $95 \%$.

GRÁFICO 4 - Efeito das turmas e intervalo de confiança segundo modelo com controle do nível socioeconômico médio das turmas - Matemática

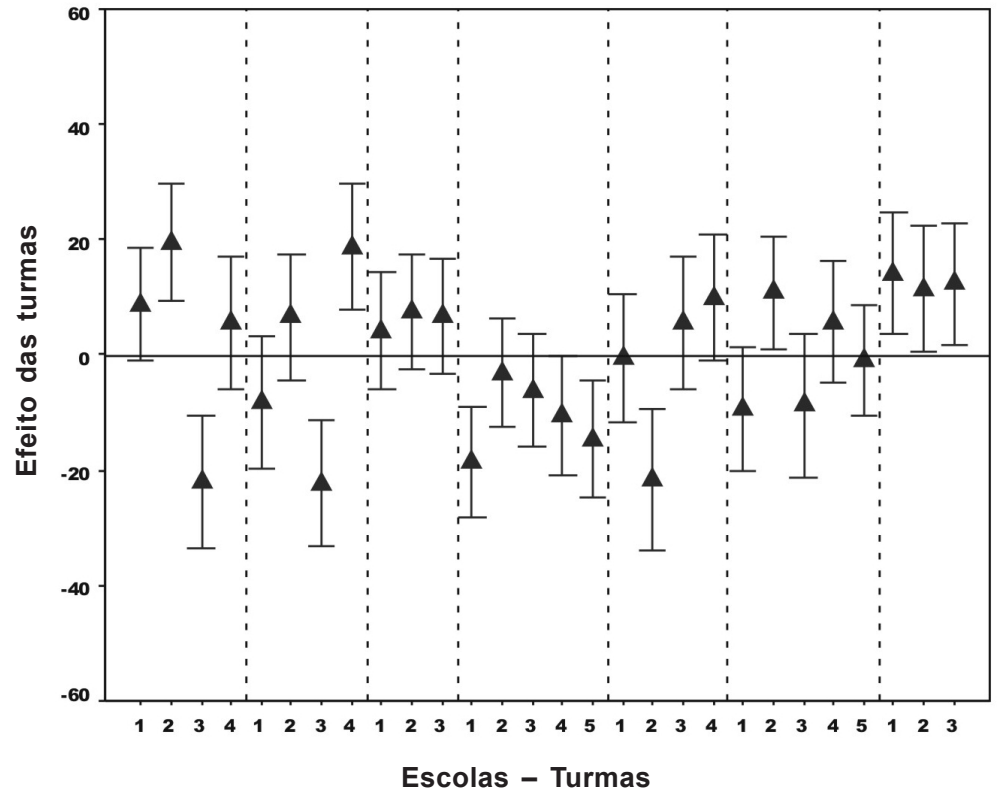

${ }^{*}$ ) significativo ao nível de $1 \%$.

GRÁFICO 5 - Efeito das turmas e intervalo de confiança segundo modelo com controle do nível socioeconômico médio das turmas - Língua Portuguesa 
Pode-se notar, em ambos os gráficos, a grande variação que existe em torno da estimativa do efeito das turmas. Além disso, os intervalos de confiança da maior parte das turmas incluem o valor zero, o que significa que não se pode concluir que os valores dos resíduos, negativos ou positivos, representem efeitos significativos. Apesar de o controle do nível socioeconômico médio das turmas retirar a contribuição de um dos fatores que influi para torná-las diferentes, é digno de nota que a maioria das escolas permanece ainda bastante heterogênea. Isso pode ser constatado pelos efeitos muito diferenciados das turmas dentro de uma mesma escola. Mas há escolas bem mais homogêneas, onde os alunos têm desempenho médio muito próximo em qualquer das turmas da escola.

O gráfico dos efeitos para os ganhos em matemática mostra que as turmas com efeitos positivos são: a turma 2 (escola 1); a turma 4 (escola 2); e as turmas 1 e 4 (escola 5). Turmas com efeitos negativos são: a turma 5 (escola 4); e as turmas 3 e 5 (escola 6). Em relação aos efeitos das turmas para os ganhos em português, as tendências são parecidas com as observadas em relação à matemática, mas a magnitude dos efeitos é mais significativa. As turmas com efeitos positivos são: a turma 2 (escola 1); a turma 4 (escola 2); a turma 2 (escola 6); e todas as turmas da escola 7. As turmas com efeitos negativos são: a turma 3 (escola 1); a turma 3 (escola 2); as turmas 1, 4 e 5 (escola 4); e a turma 2 (escola 5).

A escola 7 é a que apresenta a menor variabilidade interna entre as escolas. O controle pelo nível socioeconômico médio não altera os resultados descritivos para a escola, o que significa que a composição do grupo não constitui um fator de heterogeneidade. Em matemática, os efeitos de todas as turmas da escola são muito parecidos, equivalentes ao desempenho médio geral, porque as estimativas para o efeito de todas as turmas dessas escolas incluem o valor zero. Isso também ocorre na escola 3. Mas em língua portuguesa, além da grande homogeneidade interna, a escola 7 tem a vantagem de apresentar efeitos positivos para todas as turmas.

\section{Discussão}

As análises realizadas com os dados coletados em duas ondas mostraram que a maioria dos alunos avançou no primeiro ano da pesquisa, mas a maior parte da variação nos ganhos se deve às diferenças entre os alunos. Observou-se um impacto significativo, embora pequeno, das turmas, mas que nem sempre é o mesmo nas duas disciplinas ou para o 
mesmo tipo de aluno. Deve-se ressaltar ainda que há uma grande variação em torno do efeito-turma estimado pelos resíduos, o que inviabiliza qualquer tentativa de hierarquização das turmas (e das escolas) baseada apenas em médias. Este resultado corrobora a crítica à prática de se produzir ranking de escolas com base em estimativas pontuais de efeitos, como ocorre em alguns países (Goldstein et al., 1999; Ferrão, 2003).

É importante discutir as conseqüências para as escolas do impacto das turmas no desempenho dos alunos. O efeito do contexto das salas de aula é um dos temas privilegiados na pesquisa sobre o efeito-escola, porque em geral há muito maior variação no nível das salas de aula do que no nível das escolas. As diferenças entre as turmas podem ter relação com o número de alunos, com o conteúdo curricular ou com os critérios para a composição do grupo (por nível de conhecimento acadêmico, origem social ou por outros fatores), bem como as características dos professores (formação, experiência, habilidade etc.). ${ }^{18}$ Mas são as variáveis associadas à estrutura social da sala de aula, resultantes dos critérios adotados pela escola ou pelo sistema educacional para formar as turmas, as que mais explicam a variabilidade entre as turmas (Creemers; Jonag, 2002; Hallinan, 1994; Lamb; Fullanton, 2002).

$\mathrm{Na}$ maioria das escolas deste estudo há uma convergência entre turmas com ganhos médios piores e as características predominantes do grupo de alunos na turma, que são associadas ao pior desempenho escolar, isto é, nível socioeconômico mais baixo e atraso escolar. Estes resultados sugerem que o critério de formação das turmas dessas escolas leva em conta o nível de habilidade dos alunos, que de certa forma coincide com o nível socioeconômico. Com essa prática, as diferenças entre os alunos se potencializam e as escolas contribuem para estruturar internamente as desigualdades sociais (Hallinan, 1994). Dados coletados através das entrevistas realizadas nesta pesquisa corroboram essa idéia e exemplificam o que ocorre em muitas escolas no momento de montar as turmas, conforme o extrato destacado a seguir:

18 O efeito específico dos professores, apesar de reconhecida a importância do tema, não foi alvo de investigação nesta pesquisa. Essa possibilidade chegou a ser considerada, mas depois foi descartada pela dificuldade do campo de pesquisa. A realidade da escola se revelou muita fragmentada, porque a partir da $5^{\text {a }}$ série, ao contrário do que ocorre nos primeiros anos do ensino fundamental, os alunos passam por vários professores durante um dia letivo. Além disso, especificamente nas disciplinas matemática e língua portuguesa, houve trocas de professores durante o primeiro ano da pesquisa (por licença médica ou outros motivos) e também de um ano para o outro (da $5^{\text {a }}$ para a $6^{\text {a }}$ série) o que criou uma situação muito pouco estável para esse nível de análise. 
No ano passado [as turmas] eram bem heterogêneas, e os professores pediram turmas mais homogêneas pra eles poderem trabalhar melhor as dificuldades, ok? Como foi pedido dos professores, mesmo com a gente conversando bastante que isso não era adequado, que a gente tem que dar uma diversidade na sala, que não pode ser todo mundo igual, tanto no nível de conhecimento, quanto no nível socioeconômico, não, eles não aceitaram [...] (Entrevista com a supervisora da escola 1).

A maioria dos professores também prefere assim, com o argumento de que isso pode ser melhor para o aluno: "Atualmente são mais homogêneas e eu prefiro. Olha, quando você tem uma turma totalmente heterogênea a produção cai vertiginosamente [...] você perde inclusive bons alunos" (professora de matemática da escola 2). Essa preferência é devida também às condições de trabalho do professor: "Eu gosto de desafio, eu gosto de heterogênea, mas para o professor, na atual conjuntura, a questão de comodismo, homogêneo é muito melhor" (professora de matemática da escola 3).

$\mathrm{O}$ argumento de que a formação de turmas por habilidade melhora o ensino e aumenta a sua eficácia ao permitir que os professores adaptem a aula ao nível dos alunos é discutido por Hallinan (1994), que lembra, no entanto, que a prática cria oportunidades desiguais de aprendizado. As escolas estabelecem objetivos bem mais singelos para as turmas com nível mais baixo, sem perspectiva de alcançar alguma eqüidade. Uma professora expressou seu desânimo sobre o futuro desses alunos:

Cada ano, está ficando mais complicado trabalhar. Eu que recebo os meninos do $2^{\circ}$ ciclo, eu sinto que cada ano está ficando mais defasado. [...] Atualmente eu estou numa turma que eles não usam livro didático porque eles estão num outro processo bem aquém, então não há como acompanhar [...]. Não tem jeito. Então eu trabalho o básico (Entrevista com a professora de matemática da escola 5).

A formação de turmas por habilidade ou nível socioeconômico dos alunos não significa um processo estático de reprodução social. A literatura sugere que a composição da turma influi no conteúdo curricular, no senso de eficácia dos professores e, sobretudo, nos resultados dos alunos, através da influência dos pares (Burns; Mason, 2002). Os processos de interação entre os alunos nas escolas e nas turmas influenciam tanto os seus resultados escolares como a sua motivação, atitude e expectativas em 
relação à escola e também os aspectos não acadêmicos da formação dos indivíduos (Rutter; Maughan, 2002).

Uma professora, ao responder qual era o perfil da turma, fez uma observação sobre a influência desta no seu próprio trabalho e no grupo de alunos, o que exemplifica o efeito dos pares: "Homogêneas, são turmas homogêneas [...] Eu acho muito complicado, né? [...] porque a princípio, na turma homogênea, você corre o risco de se condicionar tanto quanto o menino, né? Você acredita que a turma tem aquele potencial só, você limita" (professora de português da escola 2).

O efeito dos pares poderia significar, em tese, um estímulo para os alunos com mais dificuldades se eles fossem agrupados junto com alunos melhores. Mas, na prática das escolas, isso não funciona, como explicou uma diretora entrevistada:

Nós já tentamos no ano retrasado ou passado... eu falei "gente, mas não pode uma turma toda com dificuldade. A gente cansa muito". Aí eu falei, "acho que a gente deveria montar turmas heterogêneas, porque uns, os que têm mais facilidade, são estímulos para os que têm menos". Fizemos, só que não deu muito certo. Aí no outro ano, eu falei "gente, vamos montar as turmas mais homogêneas que é mais fácil da gente trabalhar", e assim fizemos (Entrevista com a diretora da escola 1).

$\mathrm{Na}$ literatura, os estudos sobre as salas de aula mostram que é muito difícil levar a experiência de uma escola para outra. Hallinan (1994), por exemplo, mostra que a formação de turmas por habilidade pode ter um grande impacto em algumas escolas e menor em outras, dependendo do número de alunos por turma, da quantidade de turmas por escola em cada um dos níveis de habilidade, dos critérios objetivos (notas) ou subjetivos (avaliação dos professores ou dos pais) para agrupar os alunos em turmas, da flexibilidade para mudança entre turmas e das prioridades curriculares nas diferentes turmas.

Nas escolas municipais incluídas na pesquisa, parece haver uma maior flexibilidade para mudanças entre as turmas, apesar de os profissionais reconhecerem que não encontraram ainda uma fórmula ideal. Nestas escolas, oficialmente, o critério de formação das turmas é por idade, de acordo com cada ano dentro do ciclo. Mas há adaptações, para acomodar a diversidade de alunos atendidos nessas escolas, e a criação de turmas especiais, chamadas de "turma de projeto", para aqueles alunos 
com grandes defasagens. ${ }^{19}$ Como explicaram duas coordenadoras de escolas municipais:

$\mathrm{Na}$ verdade a gente usa vários critérios... nós temos a turma que tem muita dificuldade de aprendizagem [...]. São aqueles de nível social muito baixo, mas muito baixo mesmo, e aí interfere muito na aprendizagem [...] (Entrevista com a coordenadora da escola 5).

No início do ano, nas observações que a gente faz das questões de desenvolvimento pedagógico dos meninos, a gente faz o remanejamento. Mas o primeiro critério é aparelhamento por idade, né? Mas na hora que tiver necessidade a gente troca. [...] Avalia o pedagógico todo, a questão social [...] Não fica ótimo não, porque não tem jeito, né? Porque senão você teria, ao invés de três turmas, você teria cinco, seis turmas (Entrevista com a coordenadora da escola 6).

Entre as escolas desta pesquisa, as escolas 3 e 7 são as únicas que contrariam a tendência geral e apresentam impactos equivalentes em todas as turmas. Nessas escolas, os critérios de formação de turmas parecem mais neutros.

$\mathrm{Na}$ escola 3, a diretora explicou que os alunos, "de um modo geral, eles são agrupados por idade, entendeu? [...] O computador enturma tudo por idade”. Mas isso não é inflexível. Se há dificuldades, por exemplo, de relacionamento entre os alunos ou indisciplina, mudanças podem ser feitas de um ano para outro: "o menino não está adaptado, ele não está sentindo bem na turma, aí vem a mãe, mais não sei quem, e a gente procura atender, porque afinal o menino também tem que se sentir bem" (diretora da escola 3).

A professora de português da escola 3 confirma que a composição das turmas é equilibrada: "Não são tão homogêneas [as turmas da $5^{a}$ série]. Há alunos muito fracos até com dificuldade de aprendizagem, alunos que a gente considera que deveriam estar em escola especializada [...] e a gente tem caso de aluno com boa capacidade dentro da mesma turma" (professora de português da escola 3).

19 Nas escolas municipais, as "turmas de projeto" visam sanar deficiências, principalmente de leitura e escrita, que já deveriam ter sido alcançadas por alunos de $5^{a}$ série. Mas os dados mostram que o projeto não está tendo efeito para o crescimento acadêmico desses alunos, apesar de possivelmente ter alcançado outros objetivos que não foram medidos diretamente nesta pesquisa. 
Deve-se destacar que a escola 3 possui uma reputação reconhecida na região. Como disse uma mãe: "na região aqui, só se fala do [nome da escola]. É a escola melhor, porque você coloca, você não tem mais problema, vai até o $2^{\circ}$ grau". O baixo percentual de alunos que vão a pé para a escola mostra que ela atrai alunos de bairros distantes dela e até mesmo de outras cidades da região metropolitana. Em entrevistas com diversas famílias de alunos da escola, surpreendentemente, constatou-se que todos os pais cujos filhos estão nessa escola desde a $1^{\text {a }}$ série conseguiram vaga usando um endereço falso. Os pais "confessaram" esse desvio sem disfarçar um certo orgulho por terem conseguido colocar os filhos numa escola de boa reputação: "agora não tem mais problema, podemos contar... a gente tinha boas informações da escola, tanto é que para conseguir vaga lá nós conseguimos uma conta da Cemig como se nós morássemos lá e conseguimos para ela" (pai de aluna da escola 3). A valorização da escola, via de regra, se traduz em maior envolvimento das famílias com a escola, motivação dos alunos, mas também cobrança dos pais por resultados tanto da escola como dos filhos. ${ }^{20}$

$\mathrm{Na}$ escola 7, foi relatada uma experiência diferente para lidar com a heterogeneidade dos alunos, sem a necessidade de agrupá-los em turmas homogêneas. A fala da coordenadora explica esta prática adotada em anos anteriores, mas que não teve continuidade:

na proposta da escola plural, a enturmação é por idade, né? A gente vem respeitando isso [...] Tivemos, no ano passado, o horário zero, que era assim, nos primeiros cinqüentas minutos, toda a escola se movimentava com uma enturmação diferente. $\mathrm{O}$ aluno ficava enturmado por habilidade, aí no segundo momento ele iria com os seus pares por idade [...] Em função da algumas dificuldades de espaço na escola ele não teve continuidade esse ano (Entrevista com a coordenadora da escola 7).

Um professor da escola 7 confirmou que as turmas são "bastante heterogêneas. Não são turmas homogêneas não”. Mas ele pensa, como outros professores ouvidos na pesquisa, que "em turmas homogêneas o rendimento é maior". Ao ser indagado sobre como lidava com a heterogeneidade das turmas, ele respondeu:

20 Digno de nota que a escola 2 também possui a reputação de ser "a melhor escola pública do bairro", onde há outras escolas públicas (uma delas é a escola 5), e uma grande parcela do alunado vem de lugares mais distantes da região. 
A estratégia seria a paciência mesmo, é dar tempo ao tempo, quer dizer o ensino da disciplina flui com mais lentidão. Você tem que dar mais tempo para os exercícios, mais paciência ao explicar, entender as deficiências de cada um. Eu acho que nas turmas heterogêneas não tem outro jeito de ensinar a não ser você estar próximo individualmente daqueles alunos [...] um relacionamento mais humano com os alunos (Entrevista com o professor de matemática da escola 7). ${ }^{21}$

Diferentemente do que ocorre na escola 3, a escola 7 não é tão procurada por famílias de fora da comunidade mais próxima. Mas ao contrário de indicar um baixo prestígio, nesse caso, a presença de alunos da vizinhança é um traço favorável. A escola 7 é antiga, inserida no meio de uma área residencial onde vive o seu público em potencial e é uma escola bem pequena (oferece somente o ensino fundamental), o que limita bastante a procura por famílias de outras áreas. A escola 7 é a escola do bairro, e há uma confluência entre a escola, a comunidade e os profissionais da escola (muitos deles moradores do próprio bairro), como disse uma mãe: "inclusive a diretora da escola, a gente estudou até no mesmo colégio, eu conhecia ela"; e outra: "conheço muitas lá, a minha vizinha que mora aqui é de lá, a [professora] também"; e ainda outra mãe, enfatizando sua amizade com os profissionais da escola, comentou que "a [nome da diretora], minha xará, conheço bem, minha vizinha".

Outro aspecto significativo em relação à escola 7 é a ausência de comentários negativos sobre o projeto pedagógico da escola, como ocorreu em entrevistas com famílias de outras escolas municipais. Os pais não parecem desconfortáveis com as mudanças pedagógicas implantadas pela Escola Plural, mesmo que não entendam vários aspectos desse projeto. Por exemplo, o sistema de avaliação qualitativo da Escola Plural. Como disse uma mãe:

inclusive isso aqui [a avaliação] eu peguei na última reunião. Ela falou assim "oh, vocês agora vão ter a avaliação deles, a legenda". Isso aí é inglês! Eu não entendo nada não. Nem leio isso aí. Eu presto atenção é nisso aqui oh [risos, apontando para as ocorrências de GA - Grandes Avanços] (Entrevista com mãe de aluno da escola 7).

21 Esse professor falou que uma reivindicação da escola junto à Secretaria de Educação para o próximo ano é a redução do número de alunos por turmas, pela dificuldade que é lidar individualmente com muitos alunos por sala de aula. 
Ou seja, essa mãe traduz a avaliação qualitativa para uma forma quantitativa que faz mais sentido para ela.

Mesmo quando reclamam do projeto, vêem outros aspectos que compensam: "as municipais tudo tá sendo plural, parece que o menino perde o interesse mesmo a gente ajudando ele em casa parece que ele não é interessado, mas lá é bom eu gosto do ensino de lá. O ensino, o tratamento do pessoal de lá sabe, eu gosto" (mãe de aluno da escola 7). Ao que parece, nesta escola, a presença de algumas práticas valorizadas pelas famílias faz com que eles se sintam tranqüilos, por exemplo, a cobrança de disciplina, exigência de uniforme, os deveres de casa diários, comunicados aos pais sobre o comportamento dos filhos, segurança etc. As dissonâncias, quando existem, não interferem na valorização da escola por parte das famílias.

Os resultados das escolas 3 e 7 evidenciam que para a escola e principalmente para os alunos pode ser favorável a criação de turmas heterogêneas. Mas talvez o que contribuiu para esse efeito positivo tenha sido o fato de que as escolas 3 e 7 tenham características que aparecem na literatura como favoráveis ao trabalho com turmas heterogêneas: ${ }^{22}$ são escolas pequenas, em comparação com as outras escolas da amostra, cada uma delas tem três turmas, sendo que a escola 7 conta com vantagem de ter turmas menores; os alunos dessas escolas têm um desempenho inicial pelo menos de nível básico, em média, segundo a escala do SAEB; e as duas escolas têm uma interação bastante positiva com as famílias dos alunos. $^{23}$

22 Cohen (2000) elaborou um estudo experimental que propôs a criação de turmas heterogêneas em escolas norte-americanas. A pesquisa teve como pressuposto o fato de que os resultados educacionais refletem as desigualdades sociais entre os indivíduos, tanto aquelas que são externas à escola quanto as que se desenvolvem nas salas de aula. 0 trabalho de intervenção procurou influir na composição social das turmas, aumentando a heterogeneidade, e no conteúdo curricular, adaptando-o à nova realidade. A experiência foi bem-sucedida, porém, segundo a própria autora, os resultados são limitados e não generalizáveis para todo tipo de escola, porque a pesquisa ocorreu em escolas pequenas, localizadas fora de grandes centros urbanos. Em realidades mais complexas, por exemplo, em grandes estabelecimentos de ensino, ou onde há um percentual elevado de alunos com nível insuficiente de desempenho, com problemas disciplinares, em áreas socialmente conturbadas, em escolas com maior rotatividade de pessoal etc., a autora prevê que haveria grandes dificuldades para a distribuição equitativa dos alunos por turmas.

Conquanto os dados sobre tamanho das escolas, das turmas e o desempenho inicial sejam objetivamente características das escolas 3 e 7, a conclusão sobre a boa interação com as famílias foi resultado das entrevistas com as famílias dos alunos e com os profissionais das escolas. Isso não significa que este aspecto seja melhor nestas escolas em comparação com as outras, pois temos apenas evidências qualitativas, que não permitem generalizações. 
Muito mais difícil é a realidade das escolas que contam com um grande número de alunos que não atingiram o nível básico de habilidade. Mas os resultados mostram que a criação de turmas homogêneas por nível de habilidade não favorece aqueles que têm mais necessidades. Talvez o resultado esperado pelas escolas para esses alunos seja para outras áreas de desenvolvimento dos alunos que não o nível cognitivo. ${ }^{24}$

\section{Conclusão}

Nesta análise dos dados obtidos na pesquisa longitudinal, foram apresentados os ganhos médios dos alunos entre as duas ondas de coleta de dados nas escolas. Considerou-se esta opção mais justa para as escolas do que mostrar apenas o desempenho final, porque reflete como os alunos caminharam em termos de aprendizagem, levando-se em conta que eles têm pontos de partida diferenciados. Uma análise transversal produziria resultados muito diferentes, conforme apresentado em um estudo preliminar com os dados da primeira onda (Alves, 2003).

Os resultados obtidos confirmam, como vários estudos educacionais, que os fatores individuais prevalecem sobre os fatores contextuais na explicação dos ganhos dos alunos. Em relação às escolas, a indicação mais forte obtida foi o efeito dos critérios para a formação das turmas. Conforme a análise de Cohen (2000), as escolas têm formas internas de estruturar as desigualdades sociais, porque as oportunidades educacionais não são as mesmas em todas as turmas devido à interação do efeito contextual das salas de aula com as características dos indivíduos, o que potencializa estas últimas. Os resultados deste estudo permitem concluir nessa mesma direção, ou seja, os ganhos dos alunos refletem a interação entre a competência intelectual e o ambiente contextual das salas de aula, mais do que o da escola. Mas, sem dúvida, a decisão política sobre a forma de agrupamento dos alunos reflete as práticas pedagógicas da escola.

Por mais complicada que seja a realidade das escolas públicas, esses dados significam um alerta importante sobre como as escolas podem contribuir para reproduzir na próxima geração as desigualdades da atual geração.

24 Uma professora de uma escola municipal comentou que a escola dá importância para outros aspectos da formação dos alunos, mas, na avaliação dela, também não tem conseguido grandes avanços: “a escola plural também quer trabalhar esta questão da cidadania, e acho que a gente tem que trabalhar muito isso, mas eu não sei se eles estão sendo preparados o bastante..." (Entrevista com a professora de matemática da escola 5). 


\section{REFERÊNCIAS}

ALVES, M. T. G. Medindo o efeito-escola no desempenho escolar: perspectivas transversal e longitudinal. In: ENCONTRO ANUAL DA ANPOCS Associação Nacional de Pós-Graduação e Pesquisa em Ciências Sociais, 27, 2125 out. 2003, Caxambu-MG. [Anais Eletrônicos...] São Paulo: ANPOCS, 2003. 1 CD-ROM.

ALVES, M. T. G. Efeito-escola e fatores associados ao progresso acadêmico dos alunos entre o início da $5^{a}$ série e o fim da $6^{a}$ série do Ensino Fundamental: um estudo longitudinal em escolas públicas no município de Belo Horizonte. 2006. 202f. Tese (Doutorado em Educação). - Faculdade de Educação, Universidade Federal de Minas Gerais, Belo Horizonte, 2006.

BAKER, F. B. The Basics of Item Response Theory. 2. ed. Wisconsin: ERIC Clearinghouse on Assessment and Evaluation, 2001.

BARBOSA, M. E. F; FERNANDES, C. A escola brasileira faz diferença? Uma investigação dos efeitos da escola na proficiência em matemática dos alunos da $4^{a}$ série. In: FRANCO, C. (Org.). Promoção, ciclos e avaliação educacional. Porto Alegre: ArtMed, 2001. p. 155-172.

BOURDIEU, P.; PASSERON, J. C. A reproducão: elementos para uma teoria do sistema de ensino. Rio de Janeiro: Editora Francisco Alves, 1975.

BRESSOUX, P. Les effets du contexte scolaire sur lês acquisitions des élèves: effet-école et effets-classes en lecture. Revue Française de Sociologie, Paris, v. 36, n. 2, p. 273-294, 1995.

BRESSOUX, P. As pesquisas sobre o efeito-escola e o efeito-professor. Educação em Revista, Belo Horizonte, FAE/UFMG, n. 38, p. 17-88, 2003.

BURNS, R.; MASON, W. A. Class Composition and Student Achievement in Elementary Schools. American Educational Research Journal, Washington, v. 39, n. 1, p. 207-233, 2002.

COHEN, E. G. Equitable Classrooms in a Changing Society. In: HALLINAN, M. T. (Ed.). Handbook of the Sociology of Education. New York: Kluwer Acadmic/ Plenum Publishers, 2000. p. 265-284.

COLEMAN, J. S. et al. Equality of Educational Opportunity. Washington DC: US Government Printing Office, 1966.

COUSIN, O. Politiques et effets-établissements dans l'enseignement secondaire. In: VAN-ZANTEN, A. (Org.). L'école l'état des saviors. Paris: La Découverte, 2000. p. $139-148$.

CREEMERS, B. P. M.; JONG, R. Explaining Differences in Student Outcomes. Journal of Classroom Interaction, Houston, v. 37, n. 2, p. 16-26, 2002. 
FERRÃO, M. E.; BELTRÃO, K. I.; SANTOS, D. P. Políticas de não-repetência e a qualidade da educação: evidências obtidas a partir da modelagem dos dados da $4^{\mathrm{a}}$ série do SAEB-99. Estudos em Avaliação Educacional, São Paulo, n. 26, p. 4774, 2002.

FERRÃO, M. E. Introdução aos modelos de regressão multinivel em educação. Campinas: Komedi, 2003.

FORQUIN, J.-C. Sociologia da educação: dez anos de pesquisas. Petrópolis: Vozes, 1995.

FLETCHER, P. A Teoria da Resposta ao Item: medidas invariantes do desempenho escolar. Ensaio: Avaliação e Políticas Públicas em Educação, Rio de Janeiro, v. 1, n. 2, p. 21-28, 1994.

GOLDSTEIN, H. Multilevel Statistical Models. Londres: Edward Arnold, 1995.

GOLDSTEIN, H. et al. The use of value added information in judging schoolperformance. Londres: OFSTED, 1999.

HALLINAN, M. T. School differences in tracking effects on achievement. Social Forces, Chapel Hill, v. 72, n. 3, p. 799-822, Mar. 1994.

HOX, J.J. Applied Multilevel Analysis. Amsterdan: T'T Publikaties, 1995.

LAMB, S; FULLARTON, S. Classroom and School Factor affecting Mathematics Achievement: A comparative Study of Australia and the United States using TIMSS. Australian Journal of Education, Victoria, v. 46, n. 2, p. 154-171, 2002.

LEE, V.; BRYK, A. S. Multilevel Model of the Social Distribution of High School Achievement. Sociology of Education, Washington, v. 62, p. 172-192, Jul. 1989.

LEE, V. School Size and the Organization of Secondary Schools. In: HALLINAN, M. T. (Ed.). Handbook of the Sociology of Education. New York: Kluwer Acadmic/ Plenum Publishers, 2000. p. 327-344.

LEE, V. E. Using Multilevel Methods to Investigate Research Questions that Involve Nested Data: Examples from Education. Estudos em Avaliação Educacional, Fundação Carlos Chagas, São Paulo, n. 24, p. 47-68, jul./dez. 2001.

MOSTELLER, F; MOYNIHAN, D. P. On Equality of Educational Opportunity: Papers Deriving from the Harvard University Faculty Seminar on the Coleman Report. Nova York: Random House, 1972.

MURNANE, R. J. The impact of School Resources on the Learning of Inner City Children. Cambridge, Massachusetts: Ballinger, 1975.

NOGUEIRA, M. A. A Sociologia da educação do final dos anos 60/início dos anos 70: o nascimento do paradigma da reprodução. Em Aberto, Brasília, n. 46, p. 49-59, abr./jun. 1990.

NOGUEIRA, C. M. M.; NOGUEIRA, M. A. Bourdieu \& a Educação. Belo Horizonte: Autêntica, 2004. 
PITUCH, K. A. Describing School Effects with Residual Terms: Modeling the Interaction between School Practice and Student Background. Evaluation Review, Los Angeles, v. 23, n. 2, p. 190-211, 1999.

RAUDENBUSH, S. W.; BRYK, A. Hierarchical Linear Models: Applications and Data Analysis Methods. $2^{\text {nd. }}$ ed. Thousand Oaks: Sage Publications, 2002.

RAUDENBUSH, S. W.; WILLMS, J. D. The Estimation of School Effects. Journal of Educational and Behavioral Statistisc, Washington, v. 20, n. 4, p. 307-335, 1995.

RUTTTER, M.; MAUGHAN, B. School Effectiveness Finding: 1979-2002. Journal of School Psychology, Charlottesville, v. 40, n. 6, p. 451-475, 2002.

SINGLY, F. L'école et la famille. In: VAN-ZANTEN, A. (Org.). L'école l'état de savoirs. Paris: La Découverte, 2000. p. 271-279.

SOARES, J. F.; CÉSAR, C. C.; MAMBRINI, J. Determinantes de desempenho dos alunos do ensino básico brasileiro: evidências do SAEB de 1997. In: FRANCO, C. Promoção, ciclos e avaliação educacional. Porto Alegre: ArtMed, 2001. p. 121-153.

SOARES, J. F. et al. Fatores associados ao desempenho em lingua portuguesa e matemática: a evidência do SAEB-2003. Belo Horizonte: Laboratório de Medidas Educacionais, Instituto de Ciências Exatas, Universidade Federal de Minas Gerais, 2004. 74 p. Relatório Técnico.

SØRENSEN A. B.; MORGAN, S. L. School Effects: Theoretical and Methodological Issues. In: HALLINAN, M. T. (Ed.). Handbook of the Sociology of Education. New York: Kluwer Academic/Plenum Publishers, 2000. p. 137-160. WYATT, T. School Effectiveness Research: Dead End, Damp Squib or Smoldering Fuse? Issues in Educational Research, Sidney, v. 6, n. 1, p. 79-112, 1996. YAIR, G. School Organization and Market Ecology: a Realist Sociological Look at the Infrastructure of School Choice. British Journal of Sociology of Education, Sheffield, v. 7, n. 4, p. 453-471, 1996. 


\section{Apêndice}

\section{Ganhos MÉdios (DIFERençA MÉdia entRe A ONDA 2 e ONDA 1) E INTERVALO DE CONFIANÇA A $95 \%$}

Todas as escolas

\begin{tabular}{l|l|l|l|l|l|l}
\hline & \multicolumn{3}{|c|}{ Matemática } & \multicolumn{3}{c}{ Língua Portuguesa } \\
\hline \multirow{2}{*}{ Escolas } & \multirow{2}{*}{ Ganho Médio } & \multicolumn{2}{|c|}{ Intervalo de confiança } & \multirow{2}{*}{ Ganho Médio } & \multicolumn{2}{c}{ Intervalo de confiança } \\
\cline { 3 - 4 } & & Inferior & Superior & & Inferior & Superior \\
\hline 1 & 14,20 & 7,27 & 21,14 & 1,96 & $-7,01$ & 10,94 \\
\hline 2 & 24,99 & 19,56 & 30,41 & 22,21 & 14,71 & 29,70 \\
\hline 3 & 16,31 & 9,83 & 22,79 & 23,78 & 17,27 & 30,29 \\
\hline 4 & 14,35 & 8,93 & 19,76 & $-2,22$ & $-8,37$ & 3,92 \\
\hline 5 & 17,85 & 6,91 & 28,78 & 2,96 & $-9,55$ & 15,47 \\
\hline 6 & 8,36 & 0,40 & 16,32 & 6,13 & $-0,99$ & 13,24 \\
\hline 7 & 23,38 & 13,43 & 33,33 & 21,27 & 11,91 & 30,63 \\
\hline
\end{tabular}

Turmas da Escola 1

\begin{tabular}{l|l|l|l|l|l|l}
\hline & \multicolumn{3}{|c|}{ Matemática } & \multicolumn{3}{c}{ Língua Portuguesa } \\
\hline \multirow{2}{*}{ Turmas } & \multirow{2}{*}{ Ganho Médio } & \multicolumn{2}{|c|}{ Intervalo de confiança } & \multirow{2}{*}{ Ganho Médio } & \multicolumn{2}{c}{ Intervalo de confiança } \\
\cline { 6 - 7 } & & Inferior & Superior & & Inferior & Superior \\
\hline 1 & 14,83 & 2,43 & 27,23 & 11,87 & $-1,16$ & 24,90 \\
\hline 2 & 30,37 & 16,15 & 44,58 & 24,48 & 6,92 & 42,04 \\
\hline 3 & $-2,72$ & $-15,49$ & 10,04 & $-34,91$ & $-53,69$ & $-16,13$ \\
\hline 4 & 11,34 & $-4,10$ & 26,77 & $-1,46$ & $-20,32$ & 17,40 \\
\hline
\end{tabular}

Turmas da Escola 2

\begin{tabular}{l|l|l|l|l|l|l}
\hline & \multicolumn{3}{|c|}{ Matemática } & \multicolumn{3}{c}{ Língua Portuguesa } \\
\hline \multirow{2}{*}{ Turmas } & \multirow{2}{*}{ Ganho Médio } & \multicolumn{2}{|c|}{ Intervalo de confiança } & \multirow{2}{*}{ Ganho Médio } & \multicolumn{2}{|c}{ Intervalo de confiança } \\
& & Inferior & Superior & & Inferior & Superior \\
\hline 1 & 22,23 & 14,41 & 30,05 & 17,11 & 5,10 & 29,11 \\
\hline 2 & 18,29 & 8,48 & 28,10 & 32,86 & 21,36 & 44,35 \\
\hline 3 & 23,41 & 11,48 & 35,33 & $-4,03$ & $-22,00$ & 13,94 \\
\hline 4 & 38,77 & 23,93 & 53,60 & 46,31 & 31,76 & 60,86 \\
\hline
\end{tabular}

Turmas da Escola 3

\begin{tabular}{l|l|l|l|l|l|l}
\hline & \multicolumn{3}{|c|}{ Matemática } & \multicolumn{3}{c}{ Língua Portuguesa } \\
\hline \multirow{2}{*}{ Turmas } & \multirow{2}{*}{ Ganho Médio } & \multicolumn{2}{|c|}{ Intervalo de confiança } & \multirow{2}{*}{ Ganho Médio } & \multicolumn{2}{c}{ Intervalo de confiança } \\
& & Inferior & Superior & & Inferior & Superior \\
\hline 1 & 9,36 & $-3,08$ & 21,79 & 18,30 & 7,90 & 28,70 \\
\hline 2 & 25,10 & 12,69 & 37,51 & 23,86 & 11,82 & 35,90 \\
\hline 3 & 13,86 & 4,07 & 23,64 & 27,85 & 16,01 & 39,70 \\
\hline
\end{tabular}


Turmas da Escola 4

\begin{tabular}{l|l|l|l|l|l|l}
\hline & \multicolumn{3}{|c|}{ Matemática } & \multicolumn{3}{c}{ Língua Portuguesa } \\
\hline \multirow{2}{*}{ Turmas } & \multirow{2}{*}{ Ganho Médio } & \multicolumn{2}{|c}{ Intervalo de confiança } & \multirow{2}{*}{ Ganho Médio } & \multicolumn{2}{|c}{ Intervalo de confiança } \\
\cline { 7 - 8 } & & Inferior & Superior & & Inferior & Superior \\
\hline 1 & 13,16 & 3,59 & 22,72 & $-16,88$ & $-31,04$ & $-2,71$ \\
\hline 2 & 14,41 & 6,19 & 22,62 & 8,24 & $-3,80$ & 20,27 \\
\hline 3 & 23,98 & 11,66 & 36,31 & $-0,95$ & $-12,94$ & 11,03 \\
\hline 4 & 23,67 & 12,88 & 34,46 & 4,30 & $-4,63$ & 13,23 \\
\hline 5 & $-5,47$ & $-25,00$ & 14,07 & $-6,73$ & $-28,65$ & 15,20 \\
\hline
\end{tabular}

Turmas da Escola 5

\begin{tabular}{l|l|l|l|l|l|l}
\hline & \multicolumn{3}{|c|}{ Matemática } & \multicolumn{3}{c}{ Língua Portuguesa } \\
\hline \multirow{2}{*}{ Turmas } & \multirow{2}{*}{ Ganho Médio } & \multicolumn{2}{|c|}{ Intervalo de confiança } & \multirow{2}{*}{ Ganho Médio } & \multicolumn{2}{|c}{ Intervalo de confiança } \\
& & Inferior & Superior & & Inferior & Superior \\
\hline 1 & 29,35 & 7,50 & 51,19 & 1,62 & $-22,26$ & 25,49 \\
\hline 2 & $-1,79$ & $-28,03$ & 24,44 & $-35,59$ & $-52,04$ & $-19,15$ \\
\hline 3 & 0,06 & $-22,08$ & 22,19 & 6,69 & $-21,63$ & 35,01 \\
\hline 4 & 37,86 & 19,26 & 56,45 & 28,23 & 3,86 & 52,59 \\
\hline
\end{tabular}

Turmas da Escola 6

\begin{tabular}{l|l|l|l|l|l|l}
\hline & \multicolumn{3}{|c|}{ Matemática } & \multicolumn{3}{c}{ Língua Portuguesa } \\
\hline \multirow{2}{*}{ Turmas } & \multirow{2}{*}{ Ganho Médio } & \multicolumn{2}{|c|}{ Intervalo de confiança } & \multirow{2}{*}{ Ganho Médio } & \multicolumn{2}{c}{ Intervalo de confiança } \\
\cline { 3 - 4 } & & Inferior & Superior & & Inferior & Superior \\
\hline 1 & 12,46 & $-13,69$ & 38,61 & $-6,60$ & $-24,54$ & 11,34 \\
\hline 2 & 12,04 & 0,79 & 23,28 & 18,59 & 4,96 & 32,22 \\
\hline 3 & $-9,96$ & $-42,82$ & 22,90 & $-18,33$ & $-35,55$ & $-1,11$ \\
\hline 4 & 22,66 & 3,77 & 41,55 & 11,68 & $-7,71$ & 31,07 \\
\hline 5 & 1,60 & $-10,68$ & 13,89 & 11,01 & $-2,18$ & 24,20 \\
\hline
\end{tabular}

\section{Turmas da Escola 7}

\begin{tabular}{l|l|l|l|l|l|l}
\hline & \multicolumn{3}{|c|}{ Matemática } & \multicolumn{3}{c}{ Língua Portuguesa } \\
\hline \multirow{2}{*}{ Turmas } & \multirow{2}{*}{ Ganho Médio } & \multicolumn{2}{|c|}{ Intervalo de confiança } & \multirow{2}{*}{ Ganho Médio } & \multicolumn{2}{c}{ Intervalo de confiança } \\
& & Inferior & Superior & & Inferior & Superior \\
\hline 1 & 22,89 & 4,62 & 41,16 & 22,65 & 9,63 & 35,67 \\
\hline 2 & 20,81 & $-2,50$ & 44,12 & 21,49 & $-3,47$ & 46,45 \\
\hline 3 & 26,10 & 13,31 & 38,90 & 19,75 & 7,30 & 32,19 \\
\hline
\end{tabular}




\section{Agradecimentos}

Os autores agradecem as instituições que possibilitaram a realização da pesquisa que deu origem a este estudo: o Conselho Nacional de Desenvolvimento Tecnológico - CNPq - Brasil, através de bolsa de Doutorado, e a Fundação Ford, no âmbito da doação feita ao Grupo de Avaliação e Medidas Educacionais - GAME/FAE - UFMG. Também agradecem a leitura atenciosa dos pareceristas anônimos, cujos comentários permitiram melhorar alguns aspectos do texto.

Recebido em: 19/06/06

Aprovado em: 12/03/07 